\title{
Analisis Komperatif Kinerja Keuangan Bank Syariah dan Bank Konvensional Antara BRI dan BNI dengan Pendekatan Camel
}

\author{
Akhmadi* \\ Sekolah Tinggi Ilmu Ekonomi Graha Karya \\ Muara Bulian Jambi \\ *Correspondence email: h.akhmadijambi@gmail.com
}

\begin{abstract}
Abstrak. Bank adalah suatu lembaga keuangan yang penting sehingga perlu dijaga kinerjanya agar dapat bekerja dengan baik dan optimal. Tujuan penelitian ini adalah untuk menganalisis perbandingan kinerja keuangan bank syariah dan bank konvensional di Indonesia. Penelitian ini merupakan penelitian kuantitatif berbentuk komparatif dengan menggunakan desain perbandingan dua rata-rata dari dua populasi yang independen. Sampel pada penelitian ini adalah 2 bank syariah (Bank Negara Indonesia Syariah dan Bank Rakyat Indonesia Syariah) dan 2 bank konvensional (Bank Negara Indonesia dan Bank Rakyat Indonesia). Metode penilaian kinerja keuangan bank yang digunakan pada penelitian ini adalah CAMEL dengan rasio keuangan yaitu CAR, NPL, NIM, ROA, BOPO, dan LDR. Data dianalisis menggunakan uji beda rerata dua kelompok tidak berpasangan (independent sample t-test). Hasil penelitian ini menunjukkan bahwa terdapat perbedaan yang signifikan pada rasio NPL, ROA, BOPO, LDR antara bank syariah dan bank konvensional. Hasil analisis menunjukkan bahwa kinerja keuangan bank syariah lebih baik berdasarkan rasio NPL, NIM, BOPO, LDR. Sedangkan kinerja keuangan bank konvensional lebih baik berdasarkan rasio CAR, ROA.
\end{abstract}

Kata Kunci: Kinerja keuangan; Rasio Keuangan; Bank Syariah; Bank Konvesional

Abstract. Bank is an important financial institution so that its performance needs to be maintained in order to work properly and optimally. The purpose of this study is to analyze the comparison of the financial performance of Islamic banks and conventional banks in Indonesia. This research is a comparative quantitative research using a comparison design of two averages from two independent populations. The samples in this study were 2 Islamic banks (Bank Negara Indonesia Syariah and Bank Rakyat Indonesia Syariah) and 2 conventional banks (Bank Negara Indonesia and Bank Rakyat Indonesia). The bank's financial performance assessment method used in this study is CAMEL with financial ratios namely CAR, NPL, NIM, ROA, BOPO, and $L D R$. Data were analyzed using the mean difference test of two unpaired groups (independent sample t-test). The results of this study indicate that there are significant differences in the ratio of NPL, ROA, BOPO, LDR between Islamic banks and conventional banks. The results of the analysis show that the financial performance of Islamic banks is better based on the ratio of NPL, NIM, BOPO, LDR. While the financial performance of conventional banks is better based on the ratio of CAR, ROA.

Keywords: financial performance; Financial Ratios; Islamic Bank; Conventional Bank

\section{PENDAHULUAN}

Bank merupakan suatu lembaga yang saat ini sudah tersebar luas dan menjadi mitra untuk mencukupi kebutuhan ekomoni masyarakat, sehingga bank mempunyai peranan penting dalam perekonomian suatu negara. Bank berperan dalam pembangunan ekonomi suatu negara karena memiliki fungsi, tujuan, dan asas yang sangat mendukung pembangunan perekonomian negara. Bank juga diartikan sebagai darahnya perekonomian suatu negara, sehingga dapat dikatakan bahwa kemajuan suatu bank dapat menjadi ukuran kemajuan suatu negara.

Bank di Indonesia dibedakan menjadi bank syariah dan bank konvensional. Perbedaan bank syariah dengan konvensional yaitu pada proses pembagian dan pengembalian keuntungan yang diberikan oleh nasabah kepada lembaga keuangan dan/atau yang diberikan oleh lembaga keuangan kepada nasabah. (Muhammad, 2005) Bank konvensional menentukan harga dan mencari keuntungan kepada nasabah menggunakan cara penetapan bunga, sebagai harga untuk produk simpanannya dan produk pinjamannya. Sedangkan bank syariah menentukan harga dan mencari keuntungan berdasarkan prinsip syariah yaitu pembiayaan berdasarkan prinsip bagi hasil (mudharabah), prinsip penyertaan modal (musyarokah), prinsip jual beli barang dengan memperoleh keuntungan (murabahah), pembiayaan barang modal berdasarkan sewa murni tanpa pilihan (ijarah), atau dengan adanya pilihan pemindahan kepemilikan atau barang yang disewa dari pihak bank kepada pihak penyewa (ijarah waigtina). (Kasmir, 2014)

Bank sebaga lembaga keuangan perlu dijaga kinerjanya agar dapat berjalan dengan baik dan optimal. Kinerja keuangan merupakan hasil kegiatan operasi perusahaan yang disajikan dalam bentuk angka-angka keuangan. (Darsono and Ashari, 2007) Kinerja bank adalah gambaran dari kemampuan bank dalam mengelola aspek permodalan dan asetnya dalam hal untuk mendapatkan keuntungan. (Rivai, 2007) Penilaian kinerja keuangan bank dapat dilakukan dengan beberapa cara, salah satunya menggunakan rasio CAMEL yang terdiri dari Capital (permodalan), Asset quality (kualitas aset), Management (manajemen), Earnings 
(rentabilitas), dan Liquidity (likuiditas). Komponen tersebut dinilai menggunakan rasio keuangan suatu bank. (Mariewaty and Setyani, 2005)

Rasio keuangan dapat dilihat dari hasil laporan keuangan bank. Laporan keuangan merupakan produk atau hasil akhir dari suatu proses akuntansi. Laporan keuangan tersebut digunakan sebagai bahan informasi bagi penggunanya dan dapat digunakan untuk proses pengambilan keputusan. (Sawir, 2005). Penelitian sebelumnya yang dilakukan oleh (Anwar, 2013) menyebutkan bahwa terdapat perbedaan yang signifikan kinerja keuangan antara bank syariah dan bank konvensional berdasarkan rasio keuangan CAR, NPL, ROA, ROE, BOPO, dan LDR.

Terdapat beberapa rasio keuangan yang bisa digunakan untuk mengetahui kinerja keuangan dalam metode CAMEL, pada penelitian ini rasio keuangan yang digunakan adalah ROA, NPL, NIM, ROA, BOPO, dan LDR. Berdasarkan latar belakang tersebut, peneliti ingin menganalisis perbedaan kinerja keuangan BRI (Bank Rakyat Indonesia) dan BNI (Bank Negara Indonesia) Konvensional dengan BRI dan BNI Syariah periode tahun 2016-2020 dengan pendekatan CAMEL.

\section{Penelitian Terdahulu}

1. Wiwit Ayu Nofitasari (2015), melakukan penelitian dengan membandingkan kinerja keuangan bank syariah di Indonesia dan Malaysia pada periode tahun 2013-2014. Metode untuk mengukur kinerja keuangan pada penelitian ini adalah CAMELS. Rasio keuangan CAMELS, yang dianalisis adalah CAR, BDR, NPM, ROA, BOPO, LDR, dan MR. Penelitian ini menunjukkan hasil bahwa sebagian besar indikator kinerja keuangan bank syariah antara Indonesia dan Malaysia tidak ada perbedaan yang signifikan, yaitu pada rasio CAR, ROA, LDR, dan MR. Sedangkan rasio BDR, NPM, dan BOPO menunjukkan adanya perbedaan yang signifikan antara bank syariah Indonesia dan Malaysia. (Nofitasari, 2015)

2. Desy Nur Pratiwi (2013), melakukan penelitian untuk menilai kinerja keuangan pada bank syariah yang memiliki status sebagai bank devisa. Metode yang digunakan adalah CAMELS. Hasilnya menunjukkan bahwa kinerja keuangan Bank Syariah Mandiri sangat baik karena berada pada peringkat komposit satu dengan skor 45,753\%. Sedangkan bank Syariah Mega Indonesia tergolong dalam kategori baik dan berada pada peringkat komposit dua dengan skor $44,945 \%$. Selanjutnya bank Muamalat Indonesia tergolong dalam peringkat yang baik dengan skor sebesar 44,254\%. (Pratiwi, 2013)

3. Yuniarti Anwar (2013), melakukan penelitian dengan tujuan untuk melihat perbedaan kinerja keuangan bank syariah dan bank konvensional menggunakan metode CAMEL selama periode 20062010. Hasil penelitian menunjukkan bahwa bank syariah (Bank Syariah Mandiri) memiliki kinerja keuangan lebih baik daripada bank konvensional (Bank Negara Indonesia Persero Tbk) berdasarkan rerata rasio CAR, ROA, NPL, BOPO, LDR, dan ROE. Secara keseluruhan terdapat beda yang signifikan antara kinerja keuangan bank syariah dengan bank konvensional. (Anwar, 2013)

\section{METODE}

Jenis penelitian yang digunakan adalah penelitian kuantitatif berbentuk komparatif. Objek yang diteliti dalam penelitian ini yaitu bank konvensional (Bank Negara Indonesia dan Bank Rakyat Indonesia) dan bank syariah (Bank Negara Indonesia Syariah dan Bank Rakyat Indonesia Syariah). Penelitian ini bertujuan untuk menganalisis perbandingan kinerja keuangan antara BRI dan BNI syariah, dengan BRI dengan BNI konvensional periode tahun 2016-2020.

Sumber data yang digunakan dalam penelitian ini adalah data sekunder, yaitu data dari laporan keuangan bank yang dipublikasikan pada tahun 2016-2020 dan diambil dari laman www.bnisyariah.co.id, www.brisyariah.co.id, www.bni.co.id, dan www.bri.co.id. Variabel yang diukur yaitu CAR (Capital Adequency Ratio), Rasio NPL (Non Performing Loan), NIM (Net Interest Margin), ROA (Return On Asset), BOPO (Biaya Operasional Pendapatan Operasional), dan LDR (Loan Deposit Ratio). Cara menghitung rasio keuangan tersebut yaitu:

1. Rasio permodalan, yang diwakili oleh variabel CAR (Capital Adequency Ratio).

$\mathrm{CAR}=($ Modal/Aktiva Tertimbang Menurut Risiko $) \mathrm{x}$ $100 \%$

2. Rasio kualitas aktiva produktif, yang diwakili oleh NPL (Non Performing Loan).

NPL $=$ Total Kredit Bermasalah / Total Seluruh Kredit

3. Aspek Manajemen, yang diwakili variabel NPM (Net Profit Margin)

NPM = (laba bersih/pendapatan operasional) $\times 100 \%$

4. Rasio Rentabilitas, yang diwakili oleh variabel rasio ROA (Return on Asset) dan BOPO (Biaya Operasional Pendapatan Operasional)

$\mathrm{ROA}=($ laba bersih/total aktiva) $\times 100 \%$

$\mathrm{BOPO}=$ Biaya Operasional $/$ Pendapatan Operasional

5. Rasio Likuiditas, yang diwakili oleh variabel rasio LDR (Loan Deposit Ratio).

$\mathrm{LDR}=\{($ total utang $) /$ total deposit + ekuitas $\} \times 100 \%$

Proses analisis data untuk melihat perbedaan/membandingkan kinerja keuangan bank syariah dan bank konvensional menggunakan uji statistik independent sample t-test. Apabila nilai sig. atau nilai $p>0,05$ berarti kinerja keuangan bank syariah dan bank konvensional tidak memiliki perbedaan yang signifikan. Sedangkan apabila nilai sig. atau nilai $p<0,05$ berarti ada perbedaan signifikan antara kinerja keuangan bank 
syariah dan bank konvensional.

\section{HASIL DAN PEMBAHASAN Analisis Deskriptif}

Tabel 1 . Analisis Deskriptif Rasio Keuangan Bank Syariah dan Bank Konvensional

\begin{tabular}{ccccc}
\hline \multirow{2}{*}{ Rasio } & \multicolumn{2}{c}{ Bank Konvensional } & \multicolumn{2}{c}{ Bank Syariah } \\
\cline { 2 - 5 } & Rerata & Std. Deviasi & Rerata & Std. Deviasi \\
\hline CAR (\%) & 23,07 & 1,60 & 20,88 & 3,88 \\
NPL (\%) & 0,87 & 0,22 & 2,55 & 1,42 \\
NIM (\%) & 6,28 & 1,26 & 6,54 & 0,85 \\
ROA (\%) & 2,78 & 1,02 & 1,03 & 0,51 \\
BOPO (\%) & 73,92 & 7,77 & 89,50 & 5,29 \\
LDR (\%) & 88,14 & 2,28 & 77,74 & 4,92 \\
\hline
\end{tabular}

Sumber: data diolah
Hasil analisis deskriptif pada penelitian ini tersaji dalam Tabel 1. Rerata rasio CAR lebih tinggi pada bank konvensional dibandingkan bank syariah dengan persentase sebesar 23,07\%. Rasio NPL menunjukkan rerata yang lebih besar pada bank syariah dengan persentase sebesar 2,55\%. Selanjutnya rerata rasio NIM antara bank konvensional dan syariah hanya selisih sedikit yaitu sebesar 6,28\% pada bank konvensional dan $6,54 \%$ pada bank syariah. Rerata rasio ROA dan LDR lebih besar pada bank konvensional dengan persentase sebesar $2,78 \%$ dan $88,14 \%$. Sementara rerata rasio BOPO lebih besar pada bank syariah dibandingkan bank konvensional dengan persentase sebesar $89,50 \%$.

\section{Pengujian Hipotesis}

Tabel 2. Uji Normalitas Data dengan Kolmogorov-Smirnov

\begin{tabular}{|c|c|c|c|c|c|c|c|}
\hline & & CAR & NPL & NIM & ROA & BOPO & LDR \\
\hline $\mathrm{N}$ & & 20 & 20 & 20 & 20 & 20 & 20 \\
\hline \multirow{3}{*}{ Normal Parameters ${ }^{\mathrm{a}, \mathrm{b}}$} & Mean & 21,9780 & 1,7130 & 6,4085 & 1,9060 & 81,7080 & 82,9380 \\
\hline & Std. Deviation & 3,10328 & 1,31239 & 1,05559 & 1,18843 & 10,28446 & 6,50718 \\
\hline & Absolute & ,109 & ,283 &, 116 &, 153 &, 185 &, 149 \\
\hline \multirow{2}{*}{ Most Extreme Difference } & Positive & 079 & 283 & 101 & 153 & 185 & ,094 \\
\hline & Negative &,- 109 &,- 170 &,- 116 &,- 110 &,- 117 &,- 149 \\
\hline Kolmogorov-Smirnov Z & & ,488 & 1,264 & ,520 & ,682 & ,826 & 665 \\
\hline Asymp. Sig. (2-tailed) & & ,971 &, 082 & ,950 & ,741 &, 502 & ,769 \\
\hline
\end{tabular}

Sumber: data diolah

Tabel 2 menunjukkan hasil uji normalitas data menggunakan Kolmogorov Smirnov. Nilai Asymp. Sig. (2-tailed) rasio CAR sebesar 0,971, NPL sebesar 0,082, NIM sebesar 0,950, ROA sebesar 0,741, BOPO sebesar 0,502 dan LDR sebesar 0,769. Berdasarkan nilai tersebut, distribusi data pada penelitian ini bersifat normal karena nilai signifikansi setiap rasio keuangan > 0,05 .

Tabel 3. Independent sample t-test antara Bank Syariah dan Bank Konvensional

\begin{tabular}{cc}
\hline Rasio & $\boldsymbol{p}$ \\
\hline CAR & 0,116 \\
NPL & $0,005^{*}$ \\
NIM & 0,588 \\
ROA & $0,000^{*}$ \\
BOPO & $0,000^{*}$ \\
LDR & $0,000^{*}$ \\
\hline
\end{tabular}

*signifikan

Tabel 3 menunjukkan hasil independent sample $t$ test antara bank konvensional dan syariah. Diketahui bahwa rasio CAR dan NIM tidak menunjukkan perbedaan signifikan antara bank konvensional dan syariah ( $p>0,05)$, sedangkan rasio NPL, ROA, BOPO, dan LDR menunjukkan adanya perbedaan signifikan antara bank konvensional dan syariah $(\mathrm{p}<0,05)$.

\section{Pembahasan \\ Kinerja Keuangan CAR}

Hasil penelitian ini menunjukkan tidak adanya perbedaan yang signifikan rasio CAR antara bank syariah dan konvensional. Hal tersebut sejalan dengan penelitian (Nofitasari, 2015) yang mengemukakan bahwa tidak ada perbedaan yang signifikan rasio CAR pada perbankan konvensional. Hal tersebut diakibatkan karena nilai rerata rasio CAR tidak jauh berbeda antara bank syariah dan bank konvensional yaitu 20,88\% dan $23,07 \%$. Selain itu juga disebabkan karena modal yang dimiliki bank konvensional lebih besar dari bank syariah.

\section{Perbandingan Kinerja Keuangan NPL}

Hasil penelitian ini menunjukkan bahwa terdapat perbedaan yang signifikan rasio NPL antara bank syariah dan konvensional. Hal tersebut disebabkan karena nilai rerata rasio NPL bank syariah lebih tinggi daripada bank konvensional, yaitu 2,55\% bank syariah dan $0,87 \%$ bank konvensional. Peberdaan tersebut juga disebabkan karena kredit macet bank konvensional lebih besar daripada bank syariah. Hal tersebut sejalan dengan penelitian (Nofitasari, 2015) yang menunjukkan bahwa tidak ada perbedaan signifikan rasio NPL perbankan konvensional. 


\section{Perbandingan Kinerja Keuangan NIM}

Hasil penelitian ini menunjukkan bahwa tidak ada perbedaan yang signifikan rasio NIM antara bank syariah dan konvensional. Hal tersebut sama dengan penelitian (Nofitasari, 2015) yang menunjukkan bahwa tidak terdapat perbedaan yang signifikan pada rasio NIM perbankan konvensional. Hal tersebut diakibatkan karena nilai rerata rasio NIM tidak jauh berbeda antara bank syariah dan bank konvensional yaitu $6,28 \%$ dan $6,54 \%$. Selain itu juga disebabkan karena modal yang dimiliki bank konvensional lebih besar dari bank syariah.

\section{Perbandingan Kinerja Keuangan ROA}

Hasil penelitian ini mengungkapkan bahwa terdapat perbedaan yang signifikan rasio ROA antara bank syariah dan konvensional. Hal tersebut diakibatkan karena tingkat pengembalian laba bersih hampir sama. Hasil Penelitian tidak sejalan dengan penelitian (Anwar, 2013) yang menunjukkan bahwa terdapat perbedaan signifikan ROA perbankan konvensional dan bank syariah.

\section{Perbandingan Kinerja Keuangan BOPO}

Hasil penelitian ini menunjukkan bahwa terdapat perbedaan signifikan pada rasio BOPO antara bank syariah dan konvensional. Hal tersebut diakibatkan karena tingkat pengguna utang yang tidak jauh beda. Hasil ini tidak sejalan dengan penelitian (Nofitasari, 2015) yang menujukkan bahwa tidak terdapat perbedaan signifikan rasio BOPO bank konvensional dan syariah.

\section{Perbandingan Kinerja Keuangan LDR}

Hasil penelitian ini menunjukkan bahwa terdapat perbedaan yang signifikan rasio LDR antara bank syariah dan konvensional. Hal tersebut diakibatkan karena total kredit bank konvensional lebih besar daripada bank syariah. Nilai rerata rasio LDR bank konvensional juga lebih tinggi dibandingkan bank syariah yaitu $88,14 \%$ bank konvensional dan $77,74 \%$ bank syariah. Hasil penelitian ini sejalan dengan penelitian (Anwar, 2013) yang menemukan bahwa terdapat perbedaan signifikan LDR perbankan konvensional.

\section{SIMPULAN}

Rasio CAR dan NIM menunjukkan tidak ada perbedaan yang signifikan antara bank syariah dan konvensional. Sedangkan rasio NPL, ROA, BOPO, dan LDR menunjukkan adanya perbedaan yang signifikan antara bank syariah dan konvensional. Rasio CAR, ROA, dan LDR lebih baik pada bank konvensional dibandingkan bank syariah. Sedangkan rasio NPL, NIM, dan BOPO lebih baik pada bank syariah dibandingkan bank konvensional. Hal tersebut karena nilai reratanya lebih tinggi.

\section{DAFTAR PUSTAKA}

Anwar, Yuniarti. 2013. "Perbedaan Kinerja Keuangan Perbankan Syariah Dan Perbankan Konvensional Menggunakan Metode CAMEL (Studi Kasus Pada Bank Syariah Mandiri Dan Bank BNI)." Kolegial 1(1):9-31.

Darsono, and Ashari. 2007. Pedoman Praktis Memahami Laporan Keuangan. Yogyakarta: Andi.

Kasmir. 2014. Analisis Laporan Keuangan. 1st ed. Jakarta: PT Raja Grafindo Persada.

Mariewaty, Dian, and Astuti Yuli Setyani. 2005. "Analisis Rasio Keuangan Terhadap Perubahan Kinerja Pada Perusahaan Di Industri Food and Beverages Yang Terdaftar Di BEJ." Jurnal Akuntansi Universitas Kristen Duta Wacana 8:111.

Muhammad. 2005. Manajemen Bank Syariah. Yogyakarta: UPP AMP YKPN.

Nofitasari, Wiwit Ayu. 2015. "Perbankan Syariah Dengan Menggunakan Metode CAMELS (Studi Kasus Perbankan Syariah Indonesia Dengan Malaysia Periode 2013-2014 )." Skripsi IAIN Salatiga.

Pratiwi, Desy Nur. 2013. "Analisis Kinerja Keuangan Bank Konvensional Dan Bank Syariah Dengan Menggunakan Pendekatan CAMELS (Studi Empiris Pada Bank Syariah Yang Berstatus Sebagai Bank Devisa)." Fakultas Ekonomi Dan Bisnis Universitas Muhammadiyah Surakarta 112.

Rivai, Veithzal. 2007. Bank and Financial Institute Management. Jakarta: PT Raja Grafindo Persada.

Sawir, Agnes. 2005. Analisis Kinerja Keuangan Dan Perencanaan Keuangan. Jakarta: PT Gramedia Pustaka Utama. 